\title{
A CLINICAL STUDY ON PROPHYLACTIC IV OXYTOCIN INFUSION AT THE TIME OF INCISION IN CAESAREAN SECTION AND ITS OUTCOME IN A TERTIARY CARE HOSPITAL
}

\author{
Kasturi V. Donimath ${ }^{1}$, Vinay Raju $D^{2}$
}

1 Professor and Unit Chief, Department of Obstetrics and Gynaecology, Karnataka Institute of Medical Sciences, Hubli, Karnataka. 2Postgraduate Student, Department of Obstetrics and Gynaecology, Karnataka Institute of Medical Sciences, Hubli, Karnataka.

\section{BACKGROUND}

ABSTRACT

Postpartum haemorrhage remains a significant cause of maternal morbidity and the use of oxytocin has reduced maternal morbidity worldwide. Oxytocin is the uterotonic agent of choice in the prevention and treatment of postpartum uterine atony. Nevertheless, there is no consensus on the optimal dose and rate for use in caesarean sections. As oxytocin helps in uterine contraction, it guides in the easy extraction of baby as well as placental separation.

\section{MATERIALS AND METHODS}

It is a Descriptive study where 50 women undergoing caesarean section at KIMS, Hubballi, with mentioned exclusion criteria were included in the study. Outcome will be noted based on the difficulty in extraction of baby and placental extraction.

\section{RESULTS}

In around 40 cases baby was extracted without any assistance and in 42 cases placenta expelled on its own. None of the cases were reported with postpartum haemorrhage.

\section{CONCLUSION}

IV oxytocin infusion during caesarean sections significantly reduces postpartum haemorrhage and helps in baby extraction as well as placental expulsion.

\section{KEYWORDS}

IV Oxytocin Infusion, Postpartum Haemorrhage, Baby Extraction, Placental Expulsion.

HOW TO CITE THIS ARTICLE: Donimath KV, Raju VD. A clinical study on prophylactic IV oxytocin infusion at the time of incision in caesarean section and its outcome in a tertiary care hospital. J. Evolution Med. Dent. Sci. 2018;7(13):1577-1579, DOI: $10.14260 /$ jemds/2018/356

\section{BACKGROUND}

Postpartum haemorrhage (PPH) accounts for a quarter of maternal deaths worldwide ${ }^{1}$ and its incidence in developed

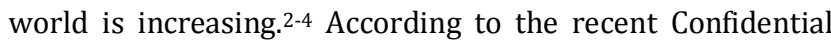
Enquiries into Maternal and Child Health (CEMACH) Report, obstetric haemorrhage occurs in around 3.7 per 1000 births with uterine atony being the commonest cause. Worldwide, PPH continues to contribute to significant maternal morbidity and mortality mainly due to 'too little being done too late.' Oxytocin (Syntocinon) is the first line of management in atonic postpartum haemorrhage. Oxytocin stimulates the fundal myometrium to contract rhythmically, which constricts spiral arteries and decreases blood flow through the uterus.(1) The variability of doses and infusion rates of oxytocin complicates a meta-analysis that contribute to the establishment of a consensus on the best use of oxytocin to prevent postpartum bleeding. Anyway, it must be remembered that oxytocin is used prophylactically in most obstetric patients as supplementation of endogenous oxytocin.

'Financial or Other Competing Interest': None.

Submission 12-02-2018, Peer Review 09-03-2018,

Acceptance 16-03-2018, Published 26-03-2018.

Corresponding Author:

Dr. Vinay Raju D

Postgraduate Student,

Department of Obstetrics and Gynaecology,

Karnataka Institute of Medical Sciences,

Hubli, Karnataka.

E-mail: vinayraju319@gmail.com

DOI: $10.14260 /$ jemds $/ 2018 / 356$

\section{(c) $(1) \ominus$}

Thus, the use of high doses (either by bolus or continuous infusion) would be unnecessary and even detrimental to patients due to the possibility of side-effects.(2)

\section{MATERIALS AND METHODS}

It is a Descriptive study, where 50 women undergoing caesarean section at KIMS, Hubballi, are included in the study. 5 units of Syntocinon was added to $500 \mathrm{~mL}$ of RL and infusion was started at the rate of 30 drops/ minute after confirming spinal action. Both elective and emergency caesarean section were included in the study with following as exclusion criteria-

- Diagnosed and clinically suspected anomalous uterus.

- Haemodynamically unstable patients.

- Compound presentation.

- Abnormal lie.

- Twin pregnancy.

- Placenta previa.

- Abruptio placenta.

- Threatened scar rupture.

- Intraoperative dense adhesions- if found the infusion stopped immediately.

\section{Outcome will be noted accordingly}

Baby Extraction-

- Grade 1 with assistance.

- Grade 2 without assistance.

\section{Extraction of Placenta-}

- Grade 1 placenta removed manually.

- Grade 2 placenta separated.

- Grade 3 placenta expelled. 
Incidence of post-partum haemorrhage noted.

\section{RESULTS}

In the 50 women who underwent caesarean section, results are as follows-

\begin{tabular}{|c|c|c|}
\hline & Number (N=50) & Percentage \\
\hline Baby extraction & 50 & 100 \\
\hline With assistance & 10 & 20 \\
\hline Without assistance & 40 & 80 \\
\hline \multicolumn{2}{|c|}{ Table 1. With Respect to Baby Extraction }
\end{tabular}

\begin{tabular}{|c|c|c|}
\hline $\begin{array}{c}\text { Weight of the } \\
\text { Babies }\end{array}$ & Number $(\mathbf{N}=40)$ & Percentage \\
\hline $3-3.5 \mathrm{~kg}$ & 08 & 20 \\
\hline $2.5-3 \mathrm{~kg}$ & 27 & 67.5 \\
\hline$<2.5 \mathrm{~kg}$ & 05 & 12.5 \\
\hline \multicolumn{3}{|c|}{ Table 2. Out of 40 Babies, which were Extracted without } \\
Assistance \\
\hline
\end{tabular}

03 babies extracted with assistance were found to be malpositioned. There was difficult in the extraction of one baby, which was after coming head of breech and intraoperatively diagnosed as unicornuate uterus.

\begin{tabular}{|c|c|c|}
\hline & Number (N=50) & Percentage \\
\hline $\begin{array}{c}\text { Placenta removed } \\
\text { manually }\end{array}$ & 02 & 4 \\
\hline Placenta separated & 06 & 12 \\
\hline Placenta expelled & 42 & 84 \\
\hline \multicolumn{2}{|c|}{ Table 3. With Respect to Placental Expulsion } \\
\hline
\end{tabular}

Among 42 placental expulsion on its own, 34 cases were previous one LSCS and 4 cases were previous 2 LSCS. 02 cases where placenta was removed manually, both were previous 2 LSCS.

Among 06 cases of placental separation, 03 were primigravida and 03 were previous one LSCS. None of the cases were reported with postpartum haemorrhage, both primary as well as secondary.

\section{DISCUSSION}

The variability of doses and infusion rates of oxytocin complicates a meta-analysis that contribute to the establishment of a consensus on the best use of oxytocin to prevent postpartum bleeding. $(3,4)$

George et al(5) studied 50 patients undergoing elective caesarean section without risk factors for uterine atony. The authors showed that oxytocin ED90 in these patients was $0.29 \mathrm{IU}$ min, which is equivalent to diluting $15 \mathrm{IU}$ of oxytocin in $1 \mathrm{~L}$ saline and infuse this solution in $1 \mathrm{~h}$. These results correspond to $50 \%$ less than the previously used infusion at the institution, where the study was conducted.

King et al(6) evaluated patients who had at least one risk factor for the development of uterine atony (uterine distention, prolonged exposure to oxytocin prior to caesarean section, chorioamnionitis and others). The use of initial bolus of oxytocin (5 IU) followed by oxytocin infusion (40 IU in 500 $\mathrm{mL}$ saline infused over 30 mins followed by $20 \mathrm{IU}$ in $1 \mathrm{~L}$ over $8 \mathrm{~h}$ ) did not alter the need for other uterotonic agent in the first 24 hrs. after caesarean section when compared with infusion alone, which was the study conducted in our institution.
With the risks and benefits of using oxytocin as a base, Tsen and Balki(7) proposed a management regime based on evidence and called "rule of threes." The authors suggest the use of $3 \mathrm{IU}$ of intravenous oxytocin (administered at higher speed than $15 \mathrm{~s}$ ) as the starting dose, which may be repeated two more times (in three minute intervals) if uterine tone is not satisfactory. The oxytocin maintenance dose is $3 \mathrm{IU} \mathrm{L}^{-1}$ at $100 \mathrm{~mL} \mathrm{~h}^{-1}$.

Langesaeter et al(8) with invasive monitoring (LiDCO Plus $\AA$ monitor) in healthy pregnant women observed an increase in cardiac index (CI), decreased systemic vascular resistance (SVR) and systolic blood pressure (BP) (range of $36-62 \mathrm{mmHg}$ ) 45 safer oxytocin injection. This same group of authors studied 18 patients with preeclampsia who underwent caesarean section 15. With the same monitoring as the previous study (LiDCO Plus ${ }^{\circledR}$ ) connected to the radial artery of patients, the authors found increased heart rate (HR) and decreased SVR and BP in all patients receiving oxytocin (5 IU) after delivery. The haemodynamic instability that can occur during postpartum haemorrhage may not be solely due to hypovolaemia, but the association of both hypovolaemia and use of oxytocin bolus in contrary there were no significant cardiovascular and haemodynamic changes in the study conducted in our institution.

However, in the UK the only recommendation available is from the RCOG 'green-top' guideline, which suggests 40 IU oxytocin in $500 \mathrm{~mL}$ saline $0.9 \%$ at a rate of $125 \mathrm{~mL} \mathrm{~h}^{1}$ for the treatment rather than the prophylaxis, of postpartum haemorrhage and uterine atony. In UK practice, this is often the same infusion regimen used for prophylaxis in high-risk cases. The RCOG does not comment on the recommended duration of infusion. ${ }^{(9)}$

\section{CONCLUSION}

A total of 50 patients who underwent caesarean section are included in the study, which comprise both elective and emergency section. In $80 \%$ of the cases baby was extracted without any assistance. 3 cases were associated with malposition in the extraction which required assistance contributing to $30 \%$ of cases requiring assistance and all 3 were primigravida. Out of 40 cases where baby was extracted without any assistance, 10 cases have unengaged head detected prior to LSCS. This study confirms that routine usage of IV oxytocin infusion prior to caesarean section not only helps in preventing PPH but also in baby extraction and placental expulsion without any major maternal and foetal adverse effects. And the same can be used in all settings with not much cardiovascular monitoring.

\section{REFERENCES}

[1] Bhide A, Arulkumaran S, Damania KR, et al. Arias' practical guide to high-risk pregnancy and delivery: a South Asian perspective. $4^{\text {th }}$ edn. India: Reed Elsevier India Pvt Ltd., 2015:389-94.

[2] Yamaguchi ET, Siaulys MM, Torres ML. Oxytocin in cesarean-sections. What's new? Braz J Anesthesiol 2016;66(4)402-7.

[3] Butwick AJ, Coleman L, Cohen SE, et al. Minimum effective bolus dose of oxytocin during elective Caesarean delivery. British Journal of Anaesthesia 2010;104(3):338-43. 


\section{Jemds.com}

[4] Weale N, Laxton C. Prophylactic use of oxytocin at caesarean section: where are the guidelines? Anaesthesia 2013;68(10):1006-9.

[5] George RB, McKeen D, Chaplin AC, et al. Up-down determination of the $\mathrm{ED}(90)$ of oxytocin infusions for the prevention of postpartum uterine atony in parturients undergoing Cesarean delivery. Can J Anaesth 2010;57(6):578-82.

[6] King KJ, Douglas MJ, Unger W, et al. Five unit bolus oxytocin at Caesarean delivery in women at risk of atony: a randomized, double-blind, controlled trial. Anesth Analg 2010;111(6):1460-6.

\section{Original Research Article}

[7] Tsen LC, Balki M. Oxytocin protocols during cesarean delivery: time to acknowledge the risk/benefit ratio? Int J Obstet Anesth 2010;19(3):243-5.

[8] Langesaeter E, Rosseland LA, Stubhaug A. Hemodynamic effects of oxytocin during Caesarean delivery. Int J Gynaecol Obstet 2006;95(1):46-7.

[9] Royal College of Obstetrics and Gynaecology. Prevention and management of postpartum haemorrhage. Green-top Guideline No. 52. London: RCOG Press 2009. 